\title{
EL DEBATE SOBRE LA LITERATURA MUNDIAL Y SUS DIMENSIONES EDITORIALES: LA REGIÓN DEL CARIBE A MODO DE EJEMPLO
}

\author{
Gesine Müller \\ Universidad de Colonia, Colonia, Alemania \\ gesine.mueller@uni-koeln.de
}

RESUMEN / ABSTRACT

\begin{abstract}
A la vista del debate actual en torno a una nueva concepción del término literatura mundial, una concepción adecuada a nuestros tiempos y que se ajuste a nuestro mundo globalizado, el artículo presente contrapone los conceptos de la "literatura mundial" y de las "literaturas del mundo". El productivo campo de tensión de estas dos teorías es puesto en relación, a su vez, con el lado material de la literatura, es decir, con los mecanismos concretos de selección del mercado del libro. A partir del ejemplo de las literaturas del Caribe, es posible comprobar, en el nivel de la práctica editorial, una interacción nueva en el uso de los conceptos de "literatura mundial" y de "literaturas del mundo": con ello se perfila ya una reorientación programática de los editores con un radio de acción global, que revalorizan ahora ciertas tradiciones literarias que antes eran declaradas periféricas.
\end{abstract}

Palabras clave: literatura mundial, literaturas del mundo, literaturas del Caribe, industria editorial, globalización.

\section{The Debate about World Literature and its Publishing Dimensions:}

THE CARIBBEAN AS AN EXAMPLE

This article contrasts the concepts of "world literature" and "literatures of the world" against the backdrop of current debates about redefining the concept of world literature in a way that is contemporary and appropriate for our globalized world. The productive tension between these two theories is linked with the material aspect of literature, meaning the specific mechanisms of selection within the book market. Focusing on the example of Caribbean literatures, this work identifies, within publishing practices, a new interplay in the use of the concepts of "world literature" and "literatures of the world": a programmatic reorientation of global publishers is emerging that is reassessing literary traditions formerly declared as peripheral. 
KEYWORDS: world literature, literatures of the world, Caribbean literatures, publishing industry, globalization.

Aprobación: 21/07/2017

\section{INTRODUCCIÓN}

El concepto de "literatura mundial", como se sabe, fue acuñado fundamentalmente por Johann Wolfgang von Goethe. Pero cuando esa concepción del término se convirtió en blanco de la crítica, la creación de cartografías de la literatura mundial siguió respondiendo a conceptos estáticos y eurocéntricos. A más tardar desde principios de la década de 1960 fue siendo cada vez más blanco de la crítica, pues representaba, para ésta, un concepto elitista de una literatura de altos vuelos que, si bien ciertamente traspasaba los marcos nacionales, era solo imaginable, al mismo tiempo, a partir de ese marco. El debate en torno al concepto de "literatura mundial", sostenido con redoblada intensidad sobre todo en los últimos dos decenios, forma parte de las controversias de los estudios culturales asociadas de forma particularmente estrecha con las cuestiones de la proliferación de redes globales en un mundo policéntrico. Mientras, por un lado, tenemos a disposición una bibliografía con diagnóstico de época sobre los funcionamientos y síntomas de crisis del actual impulso globalizador, la cual cuestiona ampliamente la hegemonía institucional, económica y cultural del norte global en relación con el sur, algunas implicaciones hegemónicas siguen impregnando su huella a las posiciones más destacadas del actual debate sobre la literatura mundial. Incluso una estudiosa como Pascale Casanova, autora del muy comentado libro The World Republic of Letters, publicado en su original francés en 1999, no renuncia en su obra a dicotomías como la de centro y periferia, todo lo contrario: Casanova ve especialmente a la ciudad de París en el centro de un "mapa de la literatura mundial" y habla de una "geografía [que] se basa en la oposición entre una capital, por un lado, y dependencias periféricas cuya relación con el centro se define por su distancia estética de él" $(12)^{1}$. La creación de la cartografía

\footnotetext{
"geography [that] is based on the opposition between a capital, on the one hand, and peripheral dependencies whose relationship to the center is defined by their aesthetic distance from it".
} 
de una historia (de la literatura) del mundo en tales dicotomías ha estampado su sello de manera duradera, obviamente, en la percepción de las supuestas literaturas periféricas, y ello resulta de capital importancia en el contexto del Caribe (véase Loy 276-277). En el caso de la creación de una nueva teoría en la fase actual de la globalización, lo importante ha de ser suprimir, desde una perspectiva global, la separación entre el centro y la periferia en lo que atañe a las producciones literarias a fin de pensar con ello la génesis de la producción cultural en constelaciones transnacionales.

El debate en torno a la "literatura mundial" será presentado a modo de breve esbozo en las siguientes reflexiones, para, más adelante, adentrarnos en las nuevas perspectivas conceptuales de las dinámicas policéntricas en el contexto de una programática de las "literaturas del mundo", siempre a partir del ejemplo de las literaturas del Caribe. En el pasado, a las literaturas del Caribe se las consideró solo de manera insuficiente como parte integrante de la "literatura mundial". Al mismo tiempo, esas mismas literaturas cumplen de forma paradigmática, casi como ninguna otra tradición literaria del mundo, los criterios que se plantean a una nueva conceptualización del término "literaturas del mundo". Relacionando el productivo campo de tensión conceptual de los dos distintos conceptos con los mecanismos típicos de la práctica de aquellas editoriales con un espectro de acción global es posible corroborar una nueva y patente interacción de ambos conceptos en el nivel de la selección editorial.

\section{EL DEBATE EN TORNO A LA “LITERATURA MUNDIAL”}

Poco después de iniciarse el nuevo milenio, los teóricos literarios estadounidenses Franco Moretti, de Stanford, y David Damrosch, de Harvard, emprendieron amplios estudios sobre el concepto de la "literatura mundial" 2 . La tesis inicial de Moretti en su ensayo "Conjectures on World Literature" partía del hecho de que la literatura mundial, en el marco de los estudios comparados, siempre constituía una empresa limitada, ya que solo hoy ésta conformaba un sistema que abarcaba a todo el planeta. En un nivel epistemológico, sin

2 Sobre este complejo temático, véase también Müller, "Literaturen der Amerikas"; Müller, "La littérature mondiale comme stratégie?"; Müller, "Konstruktion von Weltliteratur und Verlagspolitiken”; Müller, “¿Literatura mundial o literaturas mundiales?”. 
embargo, en su ensayo se piensa también, en lo esencial, en términos de dicotomías: centro y periferia, cultura de origen y cultura meta, etcétera. Las transferencias de conocimientos y de cultura tienen lugar siempre en una dirección, las obras y los autores son clasificados nítidamente dentro de una de las dos culturas y se enfrentan a determinados espacios. Por su parte, David Damrosch, aunque igualmente permanece atrapado en las categorías de lo "ajeno" y de lo "propio", muestra, en comparación con Moretti, una postura esencialmente más diferenciada en sus reflexiones, por ejemplo, sobre los procesos de circulación de la literatura (mundial) o sobre la importancia de los factores de recepción y traducción.

Aunque ya hubo en Estados Unidos, de forma aislada, algunos esfuerzos por abrir el concepto goetheano de la literatura mundial para otros discursos afirmativos de la globalización -lo cual implicaba seguir trabajando con el concepto de literatura mundial, pero sometiéndolo a una programática de la globalización más acorde con los tiempos-, no parece casual que también el proyecto de Damrosch, que en un principio parecía tan original, termine, a fin de cuentas, consolidando otra vez ciertas bipolaridades del pasado entre el centro y la periferia. Para él, la literatura mundial empieza en una literatura nacional en cierto modo constituida, tiene siempre un núcleo constituido, una esencia que parece problemática cuando se piensa en la génesis de la literatura en la fase actual de globalización acelerada: cuando el concepto implica a autores que no pueden ser clasificados con nitidez a un contexto nacional concreto, de lo que se trata entonces es de disolver la polaridad entre nación, por un lado, y el mundo, por el otro, y establecerse en un tercer espacio que, simplemente, no está previsto, en el modelo de Damrosch. Si bien este estudioso insiste -y quizá sea éste el aspecto más interesante de su libro- en la significación de los procesos de recepción y traslación, no consigue cuestionarse su propio punto de vista ni superar el binarismo entre el west ("our values", nuestros valores, Damrosch 70) y the rest (culturas que luego son recepcionadas "por nosotros"), lo que, desde una perspectiva teórico-literaria, tendría que ser la idea de un modelo de análisis universal de la literatura mundial o, por lo menos, un modelo capaz de cruzar fronteras.

C. Rajendran se aproxima a ciertas cuestiones metodológicas en la investigación de la literatura mundial en la medida en que relaciona figuras epistemológicas conceptuales de Occidente en los estudios literarios con tradiciones clásicas de recepción en la India: ¿Qué sentido tienen, ante este trasfondo, tales dicotomías como "ficción"-"no ficción" (fiction-non fiction), "real"-"maravilloso" (real-marvel) o "belleza"-"fealdad" (beauty-ugliness), 
incluso cuando éstas se refieren a la producción literaria actual? Y, por otro lado, ¿cómo pueden modificarse tales dicotomías? Joachim Küpper, quien con su compilación titulada Approaches to World Literature, del año 2013, ha reunido algunas de las voces más importantes, cuestiona en particular el acceso etnográfico hacia el debate sobre la literatura mundial en las últimas décadas. Küpper se pregunta: ¿Existe en realidad un vínculo cualquiera entre la pertenencia étnica y la cultural? ${ }^{3}$

\section{EL CONCEPTO DE LAS “LITERATURAS DEL MUNDO”}

El término "literaturas del mundo" apareció en Alemania hacia el año 2000 en el entorno de distintas instituciones del mundo literario y cultural esforzadas en adoptar una ampliación de las perspectivas en relación con este fenómeno ${ }^{4}$ : vemos, por ejemplo, que la Casa de las Culturas del Mundo, en Berlín, con dicha pluralidad, persigue el establecimiento de una exigencia programática en la transmisión de la cultura y la literatura más allá de la hegemonía occidental, y lo mismo viene a suceder con el Festival Internacional de Literatura de Berlín, que desde el año 2001 tiene una sección propia en su programa titulada "Literaturas del Mundo". El Instituto Goethe, con su programa de fomento a las traducciones desde la década de 1970, honra con el mismo término los méritos especiales de la Sociedad para el Fomento de la Literatura de África, Asia y América Latina, con lo cual se propone incluir las obras y tradiciones literarias marginalizadas dentro del mercado del libro alemán.

En el año 2004, en un ensayo, Ottmar Ette formuló las "Cinco tesis sobre una conciencia mundial y sobre las literaturas del mundo". Partiendo de la "Filología de la Literatura Mundial", de Erich Auerbach, sobre la que Ette reflexiona de manera crítica, consolida el término de "literaturas del mundo" en oposición al concepto eurocéntrico de "literatura mundial". Ese mismo año, Vittoria Borsò publicó un ensayo con el título de "Literaturas europeas versus literatura mundial. Sobre el futuro de la literatura nacional", en el cual ya se piensa el concepto de las "literaturas del mundo" en el contexto de las topografías transculturales. El término empieza a usarse con más frecuencia

\footnotetext{
Agradezco a Leonie Meyer-Krentler por estas referencias.

$4 \quad$ Sobre estas reflexiones, véase también: Müller, "Debatten nach dem postcolonial turn"; Müller y Gras.
} 
en el campo académico a partir del año 2007, por ejemplo para una serie de publicaciones de la Escuela de Graduados "Friedrich Schlegel" (Universidad Libre de Berlín) dedicada a los "estudios literarios con mayor orientación internacional, que se hayan desvinculado de la fijación exclusiva en la tradición europea y ponga su mirada en las literaturas de la modernidad europeas, americanas, árabes y asiáticas, de la Edad Media y de la Antigüedad"5.

Los estudios teóricos acuñan para ello términos diferentes: mientras que Ottmar Ette (en Viellogische Philologie [Filología multilógica]) habla de "literaturas del mundo" y con ello propaga un alejamiento radical de los eurocentrismos implícitos de múltiples maneras en el debate en torno a la "literatura mundial", Vittoria Borsò pone el estado actual de las investigaciones en relación con las "literaturas mundiales" y enfatiza el significado de los distintos conceptos de traducción en el debate, así como los distintos contextos y los condicionamientos concretos en los que surgen las literaturas mundiales. Elke Sturm-Trigonakis, por su parte, ha acuñado, en un sentido parecido, el término de "nueva literatura mundial". La crítico literaria Sigrid Löffler, en un claro esfuerzo por conseguir un canon a la altura de una época globalizada y marcada por las biografías transnacionales, utiliza ese término en su publicación sobre "La nueva literatura mundial y sus grandes narradores" (Die neue Weltliteratur und ihre großen Erzähler, 2013), dando a conocer así a un público más amplio, no familiarizado con los estudios teórico-literarios, a narradores muy destacados de rango mundial. Ha surgido, como se puede leer en la página de la editorial C.H. Beck, "una literatura completamente nueva, no occidental, escrita en la mayoría de los casos por inmigrantes o personas que han tenido que cambiar su idioma, oriundas de las antiguas colonias o de algunas regiones en conflicto. Los autores nómadas narran historias de gran colorido, con mayor exuberancia, de manera reflexiva, en los tonos más disímiles, y esas historias hablan de orígenes mestizos, de identidades híbridas, de migraciones transnacionales e integraciones difíciles".

\footnotetext{
"eine international ausgerichtete Literaturwissenschaft, die sich von der ausschließlichen Fixierung auf die westliche Tradition gelöst hat und auf die europäischen, amerikanischen, arabischen und asiatischen Literaturen der Moderne, des Mittelalters und des Altertums zielt". (http://www.geisteswissenschaften.fu-berlin.de/friedrichschlegel/Publikationen/Weltliteraturen/ index.html [29.01.2014]).

"ist eine völlig neue, nicht-westliche Literatur entstanden, die zumeist von Migranten und Sprachwechslern aus ehemaligen Kolonien und Krisenregionen geschrieben wird.
} 
Puede que tales atribuciones como "colorido" y "exuberancia" traten de nuevo de una exotización de las literaturas ya bastante conocida en el ámbito latinoamericano, por eso la importancia de un cambio de perspectiva en el contexto del debate sobre la literatura mundial está también presente en el ámbito de la producción, la publicación y distribución de literatura.

Para las reflexiones siguientes en torno a la recepción internacional de la literatura del Caribe cobran una especial significación tres de las dimensiones ya mencionadas: a) el distanciamiento de conceptos eurocentristas y de un canon eurocentrista, b) la focalización de las condiciones de surgimiento concretas para la canonización en esta fase de globalización, teniendo en cuenta los procesos de traducción concretos y las políticas editoriales, y c) una corriente nueva por su contenido en las literaturas de nuestro tiempo (sobre todo en cuanto a temas y a biografías de los autores) y en un nivel internacional y transnacional. El término "literaturas del mundo" puede abarcar esas dimensiones perfectamente dentro de las distintas variantes conceptuales, ya que muestra tanto una creación terminológica científica aun no cerrada del todo, como también retoma una práctica habitual en el ámbito editorial y literario. En la crítica literaria y en el mundo editorial, los términos "literatura mundial" y "literaturas del mundo" son empleados, a fin de cuentas, en contextos distintos, delimitables claramente los unos de los otros: pero si bien el concepto de "literatura mundial" implica todavía la significación incuestionable de una obra y fomenta con ello el valor comercial de un título o la importancia de un comentario sobre ese autor, el término "literaturas del mundo" se refiere más bien a una literatura acorde con los tiempos, de una nueva orientación, proveniente de lugares del mundo menos conocidos, pero por ello mismo muy interesantes, con un rango de mucha importancia pero que aún no ha conquistado del todo la conciencia de los lectores. Cuando se habla de ello se piensa en una mayor abundancia de material, en una visión de conjunto menos abarcable, en una convivencia de muchas obras y tradiciones y en una mayor apertura para con los criterios de selección aún no concluidos o dignos de crítica.

Nomadische Autoren erzählen farbig und prall, reflektiert und in den unterschiedlichsten Tönen Geschichten über gemischte Herkünfte und hybride Identitäten, transnationale Wanderungen und schwierige Integrationen". (http://www.chbeck.de/Loeffler-neue-Weltliteratur/productview. aspx?product=12403092 [29.01.2014]). 


\section{COMPARACIÓN ENTRE “LITERATURA MUNDIAL” Y “LITERATU- RAS DEL MUNDO”}

Cuando emprendemos una contraposición de los conceptos "literatura mundial"-"literaturas del mundo", podemos determinar, desde mi punto de vista, cinco características que son relativamente obligatorias para ambos conceptos, pero que se enfocan a menudo desde perspectivas diametralmente opuestas, con lo cual fomentan el cambio de paradigmas:

1. Multilingüismo: mientras que para la "literatura mundial" resulta de capital importancia el índice de traducciones, el criterio para las "literaturas del mundo" es la puesta en escena, en las novelas, de una pluralidad de lenguas.

2. Movimiento: la escenificación del movimiento tiene lugar, en el concepto de "literatura mundial", siempre en referencia a una perspectiva europea, mientras que las "literaturas del mundo" representan una disolución del centro y de la periferia.

3. Global-Local: la mirada hacia lo regional tiene para los adeptos de la "literatura mundial" casi siempre la intención de representar un microcosmos que viene a funcionar como sucedáneo representativo de un macrocosmos, mientras que la puesta en escena concreta de lo regional, en las "literaturas del mundo", enfatiza lo particular.

4. No-sedentarismo: el lugar de la escritura es, indirectamente, no forzosamente, la premisa para la clasificación en uno de los dos conceptos. Los autores no sedentarios cuentan con premisas privilegiadas para ser acogidos en el canon de las "literaturas del mundo".

5. Autoridad interpretativa Europa/Estados Unidos: ambos conceptos pretenden canonizar literaturas con valor universal obligatorio, si bien en el caso de la "literatura mundial" se reafirma una pretensión de autoridad interpretativa de corte occidental. Los representantes de las "literaturas del mundo" declaran obsoleta esa pretensión, pero ésta se sigue ejerciendo, en el hemisferio occidental o nórdico, de cara a los procesos de institucionalización reales.

Desde mi punto de vista, lo importante es, a la hora de comparar estos conceptos, que ambos representen dos posibilidades distintas de creación de un paradigma en la teoría literaria y en el ámbito de la cultura. Por eso no es motivo de asombro que sus criterios, muy a menudo, muestren una gran 
intersección de conjuntos en la selección de los textos literarios primarios. Y esa intersección, precisamente, se pone de manifiesto de forma muy particular y elocuente en la comercialización internacional y en la recepción de las literaturas del Caribe.

Mi tesis es que estas literaturas, las de la región del Caribe, cuentan con premisas privilegiadas para ser acogidas en el canon de las "literaturas del mundo", gracias a que cumplen muchos de los criterios mencionados. Al mismo tiempo, a partir de este inventario, es posible mostrar una interacción entre la "literatura mundial" y las "literaturas del mundo" en el nivel de la canonización editorial. O dicho más exactamente: la industria editorial de dominación occidental, a la hora de seleccionar las literaturas internacionales de regiones antes calificadas como periféricas, está aplicando en un primer nivel el filtro de selección de las "literaturas del mundo", de modo que los textos literarios que logran pasar con éxito el ojo de esa aguja pasan a convertirse, en un segundo paso, en "literatura mundial".

\section{“LITERATURA MUNDIAL” DEL CARIBE}

El universo insular del Caribe puede entenderse como un espacio de movimiento coherente $\mathrm{y}$, al mismo tiempo, heterogéneo y disparatado y marcado culturalmente hasta hoy por su cambiante pasado colonial ${ }^{7}$. Desde el llamado descubrimiento por parte de Colón en el año 1492, el universo caleidoscópico del Caribe ha reunido a diferentes grupos étnicos. Grupos de población indígena, europea, africana y asiática se entremezclan en esta región, por lo que no en vano se considera al Caribe hacia el año 1500 como un escenario de la primera fase de globalización acelerada. Esto convierte a la región en un fascinante punto de partida para los estudios de los procesos de selección de la "literatura mundial". Sus literaturas se formaron en medio de complejos procesos dinámicos de transferencia y circulación, tanto dentro de la propia región caribeña como en el intercambio con África, las dos Américas, Asia y, no en última instancia, también con Europa.

Ya a principios de la era moderna se anticipan aquí procesos y fenómenos que son de suma actualidad para nuestras sociedades de hoy: migración,

\footnotetext{
Véanse, sobre estas reflexiones, también Müller, "Les littératures caribéennes"; Müller y Neumann.
} 
circulación y creación de redes entre distintos espacios geográficos, pero también desorientación y desarraigo. Las literaturas del Caribe -según ha señalado también Birgit Neumann- representan, como ninguna otra tradición literaria, la interacción que se establece entre la desterritorialización y la concretización topográfica, siendo representativas, asimismo, de los procesos de traslación y transformación de epistemas y estéticas y una modelación literaria de la creación de redes y conexiones transterritoriales (Müller y Neumann). Es por ello que tales literaturas exigen un modo de observación que pueda hacer justicia a las dinámicas de los órdenes geopolíticos y geopoéticos, siempre tan estratificadas, fluctuantes y discontinuas (Ette, "Islands, Borders and Vectors"; Phillips Casteel; Müller, Die koloniale Karibik; Neumann y Rupp). A la vista de los intrincados entrecruzamientos de las configuraciones globales y locales, las literaturas del Caribe se encuentran tal vez más abiertas a los intentos por figurar los mundos de forma nueva y distinta -desde una perspectiva, ciertamente, subalterna-, mundos que solo son concebibles, presentables y experimentables a través de su concretización literaria o de la creación de situaciones literarias (Dünne). A las dinámicas transfronterizas de las geopolíticas caribeñas les corresponden unos métodos literarios que modelan y anticipan, desde el punto de vista estético, la creación de redes transculturales (Müller y Neumann). De ese modo, las literaturas del Caribe tienen en cuenta, en una medida que supera todo promedio, los criterios ya formulados en torno a las "literaturas del mundo". Al mismo tiempo, la recepción y la circulación de textos de autores del Caribe sigue siendo relativamente escasa en relación con los criterios de la "literatura mundial".

Los ejemplos de las literaturas caribeñas de habla inglesa constituyen un modelo del fenómeno ya abordado de las intersecciones de ambos conceptos: La literatura mundial del Caribe anglófono ya incorporada a la tradición muestra la relevancia de los reformulados criterios del no sedentarismo, de la puesta en escena del movimiento en sustitución de las lógicas centro-periferia y del énfasis de lo particular, a menudo incluso de lo archipélico. Podría decirse incluso que los textos del Caribe de habla inglesa que han sido canonizados como "literatura mundial" son aquéllos que pueden corresponder al cambio de perspectivas ya mencionado y que nos lleva hasta el concepto de literaturas del mundo: pensemos, por ejemplo, en la epopeya postcolonial Omeros, de Derek Walcott, del año 1990, una obra

en varios sentidos [...], paradigmática de la literatura mundial; no tanto por su traducción a otros idiomas como por sus historias de 
transferencia y transformación elaboradas literariamente, las cuales la hacen un espacio de experimentación muy estratificado para una conciencia universal compartida, pero situada en lo local (Müller y Neumann).

En el contexto de las lógicas de la literatura mundial y de los procesos de canonización, desempeña un papel decisivo el hecho de que los textos no tengan que ser traducidos de antemano al que sigue siendo el idioma más importante, el inglés, razón por la cual el Caribe anglófono ocupa en este trabajo una posición muy especial. Otros textos que valdría la pena mencionar y que han sido canonizados con éxito dentro de la "literatura mundial" son, por ejemplo, The Arrivants (1967-1973), de Edmund Kamau Brathwaite, Wide Sargasso Sea (1966), de Jean Rhys, The Enigma of Arrival (1987), de V.S. Naipaul, o In Another Place, Not Here (1996), de Dionne Brand.

Mientras que las literaturas del caribe anglófono han disfrutado de una amplia recepción como "literatura mundial” y, al mismo tiempo, podrían ser orientativas para los conceptos de las "literaturas del mundo", la canonización en el caso de la literatura del Caribe hispanohablante, y especialmente del Caribe francófono, solo se ha producido en casos excepcionales o no se ha producido en absoluto. En adelante, quisiera aportar algunos ejemplos aislados de esos fenómenos excepcionales en la canonización, dentro de la "literatura mundial", de obras que resultan decisivas en el contexto de los estudios en lenguas romances, a fin de trazar un boceto y comentar la formación de unas literaturas del mundo provenientes del Caribe hispanohablante y francófono ${ }^{8}$.

Ejemplo número uno: fuera de toda discusión, en lo relativo a su pertenencia al canon de la literatura mundial, están, en la primera mitad del siglo XX, el escritor nacido y crecido en la isla de Guadalupe Saint-John Perse y sus poemas (Eloges 1911; Anabase 1924; Exil 1942; Vents 1946; Amers 1957), obras que no se interesan concretamente por la realidad vital de la isla del Caribe, sino que se orientan según la poesía moderna francesa en la tradición de Arthur Rimbaud. En 1960, Saint-John Perse recibió el Premio Nobel de Literatura.

Ejemplo número dos: dentro del contexto del movimiento de la Négritude, de tal fuerza en la década de 1930 y con su sello característico originariamente

\footnotetext{
Por sus importantes sugerencias en relación, sobre todo, con las siguientes reflexiones, doy las gracias a Marion Schotsch y a Leonie Meyer-Krentler.
} 
francófono ${ }^{9}$, además de su creciente puesta de relieve de una nueva conciencia "negra", se incluye también a autores del Caribe hispanohablante. De crucial importancia en este sentido - desde la perspectiva de una "literatura mundial"es el narrador cubano Alejo Carpentier. Sus obras podrían clasificarse dentro de una variante propia de lo "real maravilloso". El concepto de "realismo mágico" que más tarde haría mundialmente famosos a varios autores latinoamericanos se remonta a un planteamiento de Alejo Carpentier en el prólogo a su novela El reino de este mundo (1949). Entre los filtros de selección para la especialmente favorable acogida de la "calidad literaria" de la obra de Carpentier están su capacidad para conectar con el surrealismo francés y un modo muy específico de la representación de la realidad, las prácticas mítico-mágicas puestas en escena como reales, lo cual tuvo gran resonancia como un elemento exótico entre el público europeo.

Ejemplo número tres: las literaturas cubanas, en su conjunto, han tenido, desde el triunfo de la Revolución cubana en 1959, una función modélica que gozó de una amplia recepción en el ámbito de la "literatura mundial". Ello está estrechamente relacionado con el llamado boom de las literaturas latinoamericanas en la década de 1960, un tema que no abordaré de manera más detallada en este ensayo. Sí aportaré, en cambio, un breve ejemplo tomado de la literatura cubana: Guillermo Cabrera Infante despliega la fuerza para imponerse literariamente a través de una dimensión política (aunque más bien anticubana), así como a través de su habilidad para conectar con procedimientos experimentales de escritura que, sobre todo, estaban ya impregnados de antemano por el nouveau roman francés. En el paisaje de la recepción europea y estadounidense, la función modélica de Cuba fue reafirmada, en el periodo que va de 1959 hasta finales de la década de 1970, por destacadas editoriales con ciertas pretensiones intelectualistas.

\section{LITERATURAS DEL CARIBE EN LA ACTUALIDAD: NUEVOS MODOS DE RECEPCIÓN EDITORIAL}

Mientras que los ya mencionados autores francófonos e hispanohablantes pueden preciarse de tener cierta recepción, especialmente en el marco de su

9 Aimé Césaire es considerado cómo ideólogo del concepto de la negritud, junto con Léopold Sédar Senghor y Léon-Gontran Damas. 
capacidad para conectar su obra con tradiciones de la cultura europea, sobre todo francesas, desde los comienzos de la década de 1990, a más tardar, se ha ido imponiendo, como se sabe, un grupo de escritores de habla francesa que, además de preciarse de su producción literaria, pueden hacer referencia a una obra ensayística de motivaciones filosóficas que se nutre del contexto de las experiencias caribeñas. El propósito de los autores reunidos en torno a Patrick Chamoiseau y a Raphaël Confiant, de la isla de Martinica, puede leerse como una variante de la implicación conceptual del multilingüismo en los textos literarios, un rasgo característico que ya he mencionado, al inicio de este ensayo, como típico de las "literaturas del mundo". Su pertenencia a esas "literaturas del mundo" se pone de manifiesto del modo más intenso en el hecho de que representa un acto de rebelión contra la asimilación cultural, un elemento esencial del debate literario en las Antillas y que engarza ya no con el contenido, sino con un nivel estético. El éxito de este lenguaje literario está teniendo consecuencias, posiblemente, para el idioma francés estándar, ya que por la vía de los grandes premios literarios -al menos desde que a Patrick Chamoiseau le fuera concedido el Prix Goncourt por su novela Texaco (1992)- se multiplican los textos escritos e impuestos en un francés oral criollo que entran en un canon literario de nuevos contornos que, en su forma tradicional, constituye la base del francés escrito. En esa tendencia se inscribe también una obra de la escritora Fabienne Kanor -nacida en Martinica en 1970-: su novela Humus (2006). A nivel del contenido, este texto opone a una rígida política de la memoria en relación con la esclavitud una nueva perspectiva: la novela, basada en un hecho real, nos habla de un grupo de esclavas que, en el siglo XVIII, a raíz de que catorce mujeres se rebelaran durante una travesía de Francia al Caribe, saltaron por la borda a modo de protesta.

La novela de Raphaël Confiant Adèle et la pacotilleuse, publicada en el año 2005, tiene lugar en la segunda mitad del siglo XIX en el Caribe, en su diáspora y en Francia. Con los recursos de una polifonía multidimensional, Confiant describe el encuentro de la hija de Victor Hugo, Adèle, con Celine, una pacotilleuse del Caribe, una vendedora de pacotilla que viaja de un lado a otro entre las islas con su mercancía. Las pacotilleuses son figuras sumamente interesantes: ponen en escena el movimiento descentralizado dentro del archipiélago caribeño y la particularidad de las distintas islas individuales, así como sus vínculos internacionales: 
Cada isla misteriosamente aficionada a un producto, una mercancía, una planta, una herramienta, pociones y ungüentos especiales, tejidos desdeñados en otros lugares. Sin embargo, gran parte de esas mercancías no provienen del Archipiélago. Todo el planeta parece desbordar sus sueños (Confiant 69) ${ }^{10}$.

Las pacotilleuses representan tanto una forma particular de solidarité géopolitique con los pueblos del Caribe como de solidarité anthropologique (o de solidarité créole) con sociedades no caribeñas marcadas también por condiciones de colonización y/o criollización similares. Son las figuras archipiélicas por excelencia, en el sentido de Édouard Glissant ${ }^{11}$.

En su novela Case à Chine, aparecida dos años después, en 2007, Confiant amplía el espacio de escenificación concreto del Caribe a su dimensión asiática, centrándose en la historia de los inmigrantes chinos en Martinica en el siglo XIX. Lo que allí se cuenta es una experiencia fundamental de las identidades del Caribe desde una perspectiva innovadora, todo en forma de los destinos de tres familias chinas que se entrecruzan, así como de su intento por huir del infierno de las plantaciones e integrarse en la vida urbana de Martinica, adaptándose a una nueva cultura y un nuevo idioma.

Una obra de Édouard Glissant, La terre magnétique: les errances de Rapa Nui, l'île de Pâques (2007), es, a su vez, parte de un proyecto que lleva por título Les peuples de l'eau [Los pueblos del agua] que el autor realiza tres años antes de su muerte y que no solo une en un estilo vanguardista el arte y la vida, sino que se abre también a nuevos espacios de movimiento: en el marco de este proyecto patrocinado por la UNESCO, un gran velero de tres palos partió en el año 2004 de la isla de Córcega con veinticuatro científicos a bordo para realizar un bojeo de circunnavegación a todo el planeta. El buque

10 "Chaque île, mystérieusement affectionne un produit, une marchandise, une plante, un outil, des philtres et des onguents particuliers, des tissus dédaignés ailleurs. Pourtant, beaucoup de tout cela ne provient pas de l'Archipel. Toute la planète semble y déverser ses rêves".

11 "La pensée archipélique convient à l'allure de nos mondes. Elle en emprunte l'ambigu, le fragile, le dérivé. [...] c'est s'accorder à ce qui du monde s'est diffusé en archipels précisément, ces sortes de diversités dans l'étendue, qui pourtant rallient des rives et marient des horizons. Nous nous apercevons de ce qu'il y avait de continental, d'épais et qui pesait sur nous, dans les somptueuses pensées de système qui jusqu'à ce jour ont régi l'Histoire des humanités, et qui ne sont plus adéquates à nos éclatements, à nos histoires ni à nos non moins somptueuses errances" (Glissant 31). 
regresó a Córcega en junio de 2007. Doce expediciones a ocho pueblos a los que solo puede accederse a través del agua, ya que habitan en islas apartadas, a orillas de ríos o en algunas costas, como los yuhup del Amazonas o el pueblo rapanui en la isla de Pascua. Varios escritores y periodistas escogidos por Glissant toman parte en cada una de las expediciones y dan testimonio del amplio radio de acción de este proyecto, el cual, sin duda, no puede medirse -al menos no únicamente- a partir de raseros ya establecidos como el de un índice de traducciones: entre los escritores están Régis Debray, Patrick Chamoiseau, J.M.G. Le Clézio, Antonio Tabucchi y André Velter.

Si echamos ahora una ojeada a las clásicas instituciones francesas que se han revelado decisivas en los procesos de canonización internacional, vemos que un momento clave fue el año 1992, cuando el prestigioso Prix Goncourt, después de más de setenta años, va a las manos de un autor oriundo de las Antillas. En 1921 lo había ganado René Maran con la novela Batouala, un acontecimiento que pasó a la historia como la primera vez que un autor declarado "negro" obtenía un importante premio literario francés. Tras una pausa que causa perplejidad, que en nada se corresponde con la producción literaria de las Antillas, recibe el premio entonces, en 1992, Patrick Chamoiseau por su novela Texaco, una obra paradigmática del concepto de "literaturas del mundo". Dentro de la más reciente producción novelística de este autor destaca particularmente Un dimanche au cachot (2007), una obra también galardonada con un premio literario francés, el Prix du Livre RFO de 2008: como sucede muy a menudo dentro del marco de la literatura caribeña contemporánea, se parte de un hecho real: en este caso se trata de la historia de una niña que se esconde en los sótanos de un orfanato y se niega a abandonarlos nuevamente, a partir de la cual el narrador Chamoiseau, que aparece en la ficción en un gesto de autorreferencialidad literaria, va desplegando una historia en torno al pasado de esos muros del sótano, un pasado que se remonta hasta la época de la esclavitud. Temas como la pérdida de identidad dentro de los límites de un orden represivo, las estrategias de supervivencia y los procesos de la búsqueda de la identidad desempeñan un papel central en un texto que muestra múltiples referencias intertextuales a obras de autores como Faulkner, Perse o Glissant.

Después de Chamoiseau, ningún premio Goncourt ha vuelto a ser concedido a un autor del Caribe, pero sí un Prix Médicis, con el que se galardonó en el año 2009 al haitiano residente en Montréal, Dany Laferrière, por su obra L'enigme du retour, un acontecimiento que puede ser considerado nuevamente un momento clave para la producción literaria caribeña y su percepción a 
nivel internacional. Marcada por una mirada desde el exterior, la novela narra la historia de una familia que oscila entre Haití y Canadá, en la cual el protagonista, un escritor haitiano en el exilio, regresa a su país de origen con motivo del entierro de su padre. El fenómeno que aquí se aborda, el cual podemos encontrar con suma frecuencia entre las "literaturas del mundo" (el fenómeno del escritor no sedentario) desempeña también un papel fundamental en la obra del varias veces premiado autor haitiano Louis-Philippe Dalembert, lo mismo en su aspecto literario como biográfico,

[...] hasta el punto de que parece no pertenecer a un lugar específico, sino a todos los lugares a la vez. Su vocación de escritor vagabundo, incapaz de echar raíces en ninguna parte, se refleja en su obra poética y su obra narrativa de sus primeras publicaciones, de modo que el vagabundeo físico se convierte también en un deambular literario entre géneros y lenguajes (Vignoli 29) ${ }^{12}$.

Sus novelas más recientes elaboran de forma consecuente esta idea del vagabundeo como fenómeno existencial de todo individuo caribeño que escribe; lo vemos, por ejemplo, en Les Dieux voyagent la nuit (2006). En esta novela de corte autobiográfico se trata de la participación del narrador en un ritual vudú en Nueva York y de un viaje de regreso al Haití de su infancia, donde le estaba prohibida la participación en tales prácticas, y todo descrito en una atmósfera onírica, alternando entre el créole y el francés parisino.

Tales homenajes a los autores caribeños a través del sistema de los prestigiosos premios literarios son todavía hoy fenómenos excepcionales. Resulta interesante ver, sin embargo, que la editorial Gallimard, la primera en publicar a Glissant, Confiant y Chamoiseau, representa en los últimos años a cada vez más autores del Caribe francoparlante, después de que, durante mucho tiempo, estuvieran muy bien representados en ella, de un modo incluso desproporcionado, otros autores antillanos como el ya mencionado ejemplo de Alejo Carpentier. Como detonante podríamos considerar el muy citado manifiesto, publicado por Gallimard en el año 2007, Pour une littératuremonde, en el que participaron numerosos autores prestigiosos como Maryse

12 'au point qu'il semble ne pas appartenir à un lieu précis mais à tous les lieux à la fois. Sa vocation d'écrivain vagabond, incapable de s'enraciner quelque part, se reflète dans son œuvre poétique et romanesque dès ses premières publications, et le vagabondage physique devient aussi un vagabondage littéraire dans les genres et dans les langues". 
Condé, Édouard Glissant, Fabienne Kanor y Dany Laferrière; un manifiesto decididamente contrario a la lógica del centro y la periferia en el concepto de la francofonía. Por otra parte, podemos observar que estos autores caribeños de Gallimard representan con fuerza los criterios de las "literaturas del mundo".

\section{RESUMEN / PERSPECTIVA}

Las literaturas del Caribe están casi predestinadas a ser acogidas en el canon de las "literaturas del mundo". Al mismo tiempo, de cara a este breve inventario de la editorial Gallimard, y posiblemente mucho más allá de ella, se perfila el establecimiento creciente de una interacción entre el criterio de la "literatura mundial", que contempla un índice de traducciones, y las "literaturas del mundo" en el nivel de las canonizaciones editoriales: lo que desde hace mucho tiempo es válido para las literaturas del Caribe anglófono, puede observarse también en la actualidad en el mercado del libro en Francia: la creciente importancia que cobra para la industria editorial, a la hora de seleccionar a autores del Caribe, el criterio de las "literaturas del mundo". Los textos literarios que han conseguido pasar con éxito el primer filtro de selección atraviesan a continuación todas las demás instancias decisivas para una canonización internacional, instancias que siguen estando todas particularmente en el mundo occidental, en nuestro caso concreto, en Francia. Este diagnóstico de una creciente circulación internacional de "literaturas del mundo" sobre la base de políticas editoriales concretas constituye una observación que aún merece ser estudiada con mayor detenimiento y sistematicidad.

Se trata de un proceso que solo podemos celebrar de cara al potencial del concepto de "literaturas del mundo". Una nueva "literatura mundial" orientada hacia las "literaturas del mundo" ha de ir desligándose cada vez más de las perspectivas eurocéntricas, ha de incluir nuevas dinámicas y espacios de recepción, así como reflexiones teóricas sobre el poder, a fin de poder interpretar, a la altura de nuestros tiempos, un sistema altamente complejo de procesos de selección y circulación y reflexionar sobre ellos críticamente en sus asimetrías. Cabe esperar que, en todo ello, para la industria editorial no solo desempeñe un papel el argumento de las cifras de venta. A las editoriales les hace bien posicionarse no solo desde el punto de vista económico, sino también conceptual. En el nivel de los procesos de producción y distribución para las literaturas del Caribe en el mercado del libro global, aún no es posible hablar de un cese actual de la hegemonía del 
norte, como se postula en muchos ámbitos de cara a los estudios referentes a la actualidad en torno a las redes globales. Puede que en algún momento se perfile una reorientación programática por parte de los editores que actúan a nivel global, con el propósito de revalorizar tradiciones literarias anteriormente declaradas periféricas.

\section{BIBLIOGRAFÍA}

Auerbach, Erich. "Philologie der Weltliteratur". Gesammelte Aufsätze zur romanischen Philologie. Ed. Fritz Schalk y Gustav Konrad. Berna y Múnich: Francke, 1967. 301-310.

Borsò, Vittoria. "Europäische Literaturen versus Weltliteratur - Zur Zukunft von Nationalliteratur". Jahrbuch der Heinrich-Heine-Universität Düsseldorf. Düsseldorf: DUP, 2003. 233-250.

Casanova, Pascale. The World Republic of Letters. Cambridge, Mass., et al.: Harvard UP, 2007. [En español: Casanova, Pascale. La república mundial de las letras. Trad. Jesús Zulaika. Barcelona: Anagrama, 2001].

Confiant, Raphaël. Adèle ou la pacotilleuse. Paris: Mercure de France, 2005.

Damrosch, David. What is World Literature?. Princeton: Princeton UP, 2003.

Dünne, Jörg. "Dynamisierungen: Bewegung und Situationsbildung”. Handbuch Literatur \& Raum. Ed. Jörg Dünne y Andreas Mahler. Berlín: De Gruyter, 2015. 41-54.

Ette, Ottmar. "Erich Auerbach oder Die Aufgabe der Philologie”. Traditionen der Entgrenzung. Beiträge zur romanistischen Wissenschaftsgeschichte. Ed. Frank Estelmann, Pierre Krügel y Olaf Müller. Fráncfort del Meno, et al.: Peter Lang, 2003. 22-42.

"Wege des Wissens. Fünf Thesen zum Weltbewußtsein und den Literaturen der Welt". Lateinamerika. Ordnungen und Orte des Wissens. Texto conmemorativo dedicado a Birgit Scharlau. Ed. Sabine Hofmann y Monika Wehrheim. Tubinga: Narr, 2004. 169-184.

"Islands, Borders and Vectors: The Fractal World of the Caribbean". Caribbean Interfaces. Ed. Lieven d'Hulst, et al. Ámsterdam y Nueva York: Rodopi, 2007. 109-152.

Viellogische Philologie. Die Literaturen der Welt und das Beispiel einer transarealen peruanischen Literatur. Berlín: edition tranvía/Walter Frey, 2013.

Glissant, Édouard. Traîté du tout-monde. París: Gallimard, 1997.

Küpper, Joachim (Ed.). Approaches to World Literature. Berlín: Akademie-Verlag, 2013.

Löffler, Sigrid. Die neue Weltliteratur und ihre großen Erzähler. Múnich: Beck, 2014.

Loy, Benjamin. "Deseos de mundo. Roberto Bolaño y la (no tan nueva) literatura mundial". América Latina y la literatura mundial: Mercado editorial, redes globales y la invención de un continente. Ed. Gesine Müller y Dunia Gras Miravet. Madrid y Fráncfort del Meno: Iberoamericana/Vervuert, 2015. 273-293.

Moretti, Franco. “Conjectures on World Literature”. New Left Review 1 (2000): 54-68.

Müller, Gesine. Die koloniale Karibik: Transferprozesse in hispanophonen und frankophonen Literaturen. Berlín: De Gruyter, 2012. 
"Literaturen der Amerikas und ihre Rezeption in Deutschland. Weltliteratur als globales Verflechtungsprinzip". Verlag Macht Weltliteratur. Ed. Gesine Müller. Berlín: edition tranvía/Walter Frey, 2014. 117-132.

"La littérature mondiale comme stratégie? Les littératures francophones et hispanophones chez Suhrkamp, objet d'une romanistique interculturelle". Dossier: La romanistique allemande. Ed. Michel Espagne y Hans-Jürgen Lüsebrink. Revue germanique 19 (2014): 65-79.

"Konstruktion von Weltliteratur und Verlagspolitiken. Der Lateinamerika-Nachlass des Suhrkampverlags". Buchmarkt, Buchindustrie und Buchmessen in Deutschland, Spanien und Lateinamerika. Ed. Marco Thomas Bosshard. Berlín y Münster: LIT, 2015. 147-160.

"¿Literatura mundial o literaturas mundiales? Un estudio de caso de las letras latinoamericanas en la editorial Suhrkamp". América Latina y la literatura mundial: mercado editorial, redes globales y la invención de un continente. Ed. Gesine Müller y Dunia Gras Miravet. Madrid: Vervuert-Iberoamericana, 2015. 81-98.

"Debatten nach dem postcolonial turn". Handbuch Weltliteratur. Ed. Vittoria Borsò. Berlín: De Gruyter (en prensa).

"Les littératures caribéennes entre littérature mondiale et littérature-monde". Dossier: Les Antilles et les littératures du monde. Ed. Ottmar Ette y Gesine Müller. Lendemains (en prensa).

Müller, Gesine y Dunia Gras Miravet. "Introducción”. América latina y la literatura mundial: mercado editorial, redes globales y la invención de un continente. Ed. Gesine Müller y Dunia Gras Miravet. Madrid: Vervuert-Iberoamericana, 2015. 9-20.

Müller, Gesine y Birgit Neumann. "Weltliteraturen in den Amerikas: Die Karibik (englisch, französisch, spanisch)”. Handbuch Weltliteratur. Ed. Vittoria Borsò. Berlín: De Gruyter (en prensa).

Neumann, Birgit y Rupp, Jan. "Sea Passages: Cultural Flows in Caribbean Poetry". Atlantic Studies: Literary, Cultural, and Historical Perspectives 13/4 (2016): 472-490.

Phillips Casteel, Sarah. "The Language of Landscape: A Lexicon of the Caribbean Spatial Imaginary". The Routledge Companion to Anglophone Caribbean Literature. Ed. Michael Bucknor y Alison Donnell. Londres y Nueva York: Routledge, 2011. 480-489.

Rajendran, C. "The Actual and the Imagined. Perspectives and Approaches in Indian Classical Poetics". Approaches to World Literature. Ed. Joachim Küpper. Berlín: Akademie-Verlag, 2013. 121-131.

Sturm-Trigonakis, Elke, Global Playing in der Literatur. Ein Versuch über die Neue Weltliteratur, Würzburg: Königshausen \& Neumann, 2007.

Vignoli, Alessia. "Louis-Philippe Dalembert, 'vagabond jusqu'au bout de la fatigue'”. Il Tolomeo 18 (2016): 29-40. 